\title{
Tecnologias na Educação Básica: uma Pesquisa Ação com Professores de uma Escola Pública Municipal
}

\author{
Katyeudo Karlos de S. Oliveira ${ }^{1}$, Carlos Williamy L. Andrade ${ }^{1}$, José Diener F. \\ Marques Segundo², Adriano L. Cândido², Augusto César Ferreira de M. Oliveira ${ }^{1}$, \\ Alexsandro dos S. Machado ${ }^{1}$, Alex C. de Britto ${ }^{1}$, Guilherme Vilar ${ }^{1}$ \\ ${ }^{1}$ Programa de Pós-Graduação em Informática Aplicada (PPGIA) \\ Universidade Federal Rural de Pernambuco (UFRPE) \\ Rua Dom Manoel de Medeiros, s/n, Dois Irmãos, CEP 52171-900, Recife - PE - Brasil \\ ${ }^{2}$ Faculdade Vale do Salgado (FVS), \\ Avenida Monsenhor Frota, 609, Centro, CEP 63.430-000 - Icó - CE - Brasil \\ \{karlos.1914.so, carloswilliamylourenco, auguustocesarf, alexdesapucaia, \\ alexcabral26\}@gmail.com, \{josediener, adriano\}@fvs.edu.br
}

\begin{abstract}
With the evolution of Information and Communication Technologies (ICT), education has changed in the school environment. However, few teachers use such technologies in their didactics. In order to contribute and streamline the teaching-learning process, the EDUCATECH project was implemented in a municipal public school. This paper analyzes the results of a questionnaire with a quantitative approach applied during the project. The results point to a great positive impact, since learning and teaching improved considerably in the referred school.
\end{abstract}

Resumo. Com a evolução das Tecnologias da Informação e Comunicação (TIC), a educação sofreu mutações no ambiente escolar. Porém, poucos professores utilizam tais tecnologias em sua didática. Visando contribuir e dinamizar o processo de ensino-aprendizagem, o projeto EDUCATECH foi implantado numa escola pública municipal. Este trabalho analisa resultados de um questionário com abordagem quantitativa aplicado no decorrer do projeto. Os resultados apontam grande impacto positivo, visto que o aprendizado e ensino melhoraram de forma considerável na escola referida.

\section{Introdução}

Com a chegada do computador e a expansão da conectividade, foi proporcionada a união dos diversos meios de comunicação, passando a coabitarem e se absorverem. No âmbito educacional, por consequência, é visto uma grande mutação tecnológica de impacto decisivo no ambiente escolar [Santaella, 2007, p. 128].

$\mathrm{Na}$ escola, as Tecnologias da Informação e Comunicação (TIC) são componentes integrantes do ambiente de ensino-aprendizagem. Elas têm a capacidade de colaborar com a aprendizagem de temáticas e no aperfeiçoamento de competências específicas. Possibilitam a desenvolvimento de áreas de comunicação $\mathrm{e}$ compartilhamento, devido às possibilidades que proporcionam em relação a transmissão e troca de informações. Consistem, também, em um instrumento de trabalho do educador e uma parte adicional da sua cultura profissional, devido às perspectivas 
VIII Congresso Brasileiro de Informática na Educação (CBIE 2019)

Anais do XXV Workshop de Informática na Escola (WIE 2019)

alternativas de manifestação criativa, de promoção de projetos e de raciocínio crítica [Pacheco, 2001]. Porém, poucos professores têm domínio relativo as novas tecnologias, da potencialidade das ferramentas e idealizar de forma eficaz métodos didáticos que representem o entendimento de como as TIC podem ser manuseadas para aperfeiçoamento da educação [García-Valcárcel and Martín, 2013].

Neste sentido, este trabalho objetiva analisar a aplicação de TIC no processo de ensino-aprendizagem de educandos do ensino fundamental de uma escola pública municipal. Ainda, o estudo visa contribuir para a compreensão da problemática atual da integração curricular das TIC, pois tal abordagem poderá nortear as orientações curriculares e promover a utilização destas tecnologias. A pesquisa é quantitativa e exploratória, para tanto, foi aplicado um questionário como técnica de coleta de dados.

O trabalho está organizado da seguinte forma: a Seção 2 descreve o projeto EDUCATECH. A Seção 3 apresenta um estudo quantitativo como avaliação do projeto. Finalmente, a Seção 4 apresenta a conclusão e trabalhos futuros.

\section{Projeto EDUCATECH}

O Projeto EDUCATECH atende um público compreendido nas turmas de $8^{\circ}$ (oitavo) e $9^{\circ}$ (nono) ano, de uma escola pública municipal. Foi implantado pela necessidade de um estudo mais aprofundado sobre os conceitos e processos de utilização da TIC na educação e conscientização da importância de um projeto voltado a esse público. $\mathrm{O}$ projeto é desenvolvido por alunos do curso de Análise e Desenvolvimento de Sistemas de uma Instituição de Ensino Superior. Visando contribuir e dinamizar o processo de ensino-aprendizagem, o projeto aplicou metodologias voltadas a aulas criativas e motivacionais, utilizando estratégias compreendidas nas TIC para que fosse possível melhorar a aprendizagem dos educandos. As ações foram desenvolvidas em conjunto com o conteúdo que o professor aplicava nas aulas.

Mensalmente a equipe de desenvolvimento do projeto se reunia com os professores e planejavam as ações que seriam realizadas na sequência. Na aplicação, o corpo docente da escola acompanhava todas as ações e também as avaliações, tendo em vista que os mesmos auxiliavam nas metodologias propostas, contribuindo para processo ensino-aprendizado, conciliando aulas criativas, motivadoras e dinâmicas.

Durante o desenvolvimento do projeto, foi utilizada a robótica para que fosse possível um melhor desenvolvimento de habilidades, como o trabalho mútuo, o raciocínio lógico e a criatividade. Tal modelo apoia-se no desenvolvimento de cenários de aprendizagem que unem materiais de montagem formados por peças variadas (Lego), interativas e manipuláveis por computador por intermédio de softwares que viabilizam a programação do funcionamento dos protótipos criados. Essa interação desenvolve um ambiente de entusiasmo e comprometimento por parte dos alunos, conseguindo relacionar-se com outras áreas do conhecimento, produzindo ações no meio interdisciplinar, no qual os estudantes experimentam de maneira prática conceitos vistos anteriormente em sala de aula [Neto et al., 2015].

Também, utilizou-se a realidade virtual possibilitando criar experiências lúdicas, auxiliando, assim, para o melhor envolvimento da turma e um efeito positivo no processo de aprendizado. Com tal tecnologia, tem-se a capacidade de representação de uma vasta variedade de cenários voltados para inúmeros planos de aplicação, tais como: jornadas virtuais em ambientes reais (museus, relevos, etc.) ou fictícios e representação 
VIII Congresso Brasileiro de Informática na Educação (CBIE 2019)

Anais do XXV Workshop de Informática na Escola (WIE 2019)

de objetos (carros, máquinas, etc.) ou representações de indivíduos reais (homem, animal, etc.) ou ilusórios (alienígenas) [Marçal et al., 2005].

Como método de revisão de conteúdo, mensalmente era desenvolvido um quiz online com o aplicativo Kahoot, recurso gratuito, disponibilizado pela web, com perguntas elaboradas previamente pelos professores, para tanto, foi necessário o uso de computadores pelos estudantes possibilitando o acesso à ferramenta. Kahoot é um jogo digital que pode ser utilizado em salas de aula para envolver os alunos no conteúdo de uma forma divertida. O jogo não só promove um ambiente de aprendizagem divertido, mas também desafia os alunos no processo de ensino-aprendizagem [Dellos, 2015].

\section{Resultados e Discussão}

Tendo o propósito de avaliar aspectos envolvendo as TIC, foi utilizado um questionário como instrumento de coleta de dados, o mesmo contendo 4 (quatro) perguntas objetivas, que abordaram os principais conceitos do desempenho obtido, impacto causado no cotidiano proporcionado pelo ensino em conjunto com as TIC e o grau de complexidade encontrado pelos professores na utilização das tecnologias. Foi realizado com docentes de uma escola pública municipal, com uma quantidade de 9 (nove) participantes.

Observando o gráfico 1 , pode-se notar que $66,7 \%$ dos participantes afirmaram que o impacto causado pelas foi positivo, assim como 33,3\% consideraram ligeiramente positivo. Não havendo respostas negativas em relação ao impacto das TIC no aprendizado escolar. Portanto, os entrevistados foram impactados de forma positiva com a utilização de tais tecnologias no aprendizado escolar. Dessa forma, as TIC podem ser consideradas como um dos importantes responsáveis pelas transformações no aprendizado. Nas escolas, são um complemento essencial às práticas pedagógicas, pois oferecem a todos os alunos, um apoio de trabalho muito abundante e intensificado [Pires, 2009]. A introdução das TIC na educação pode ser um significativo instrumento para a aperfeiçoamento do processo de ensino-aprendizagem [Leite et al., 2012].

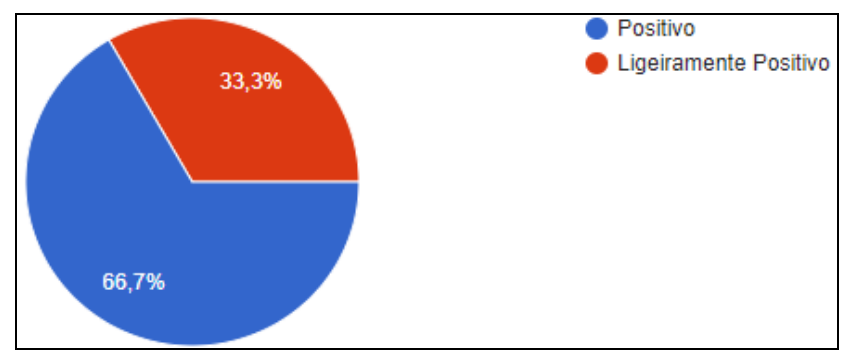

Gráfico 1. Impacto proporcionado pelas TIC no aprendizado escolar.

No gráfico 2, buscou-se avaliar também a aceitação dos alunos, avaliando-se sob um ponto de vista dos docentes. Uma porcentagem de 55,6\% avaliou como muito alta, $33,3 \%$ como alta e $11,1 \%$ regular. Considerando tais resultados mais de $85 \%$ tiveram uma aceitação plausível. Conclui-se que, nenhum professor julgou como não aceitável o uso de tecnologias no meio educacional. Com isso, pode-se observar que esta forma de ensino teve um alto índice de aprovação entre os alunos. Tal questionário, entra em acordo com [Bizelli; Fiscarelli and Oliveira, 2009] quando o mesmo relata em seu estudo que as TIC quando são disponibilizadas em sala de aula trazem grandes benefícios ao processo de ensino e aprendizagem. 
VIII Congresso Brasileiro de Informática na Educação (CBIE 2019)

Anais do XXV Workshop de Informática na Escola (WIE 2019)

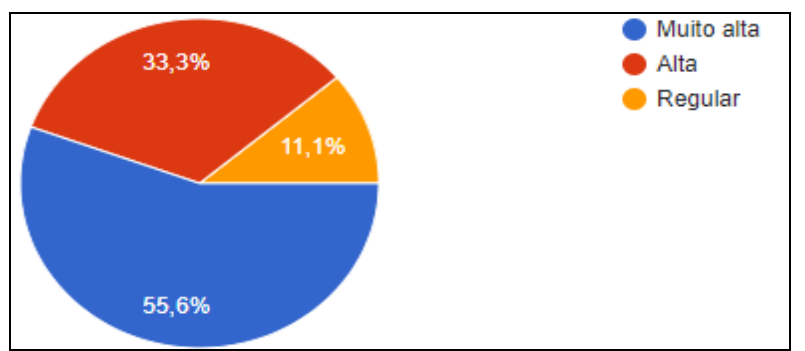

Gráfico 2. Visão dos docentes sobre o grau de aceitação das TIC entre os alunos.

No gráfico 3, 66,7\% dos professores consideraram uma maior taxa de absorção de informações por parte dos alunos. Assim como, 22,2\% se mostram semelhantes, avaliando que pelo menos um pouco mais de informações foram absorvidas pelos alunos. Ainda, 11,1\% associaram a muito pouco. Revelando assim, uma grande porcentagem positiva de $88,9 \%$ em concordância deste benefício. Visto que, a incorporação das TIC ao processo educacional, pode proporcionar mudanças significativas no ambiente escolar e, na forma como o ensino e a aprendizagem acontecem, considerando os recursos que as TIC podem oferecer [Prata, 2005].

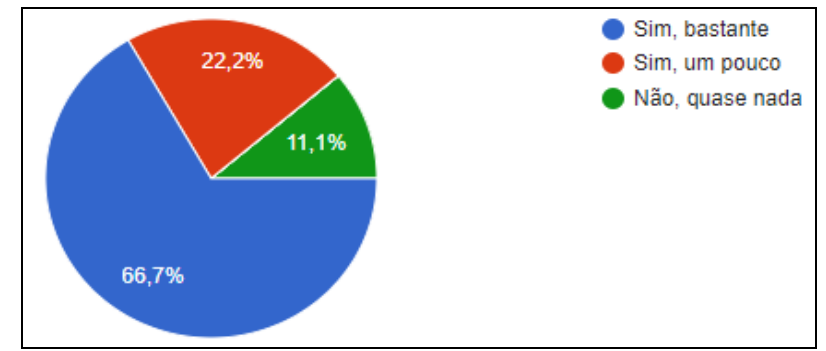

\section{Gráfico 3. Interação com o conteúdo e absorção de mais informações após a utilização das TIC.}

Os resultados do quarto gráfico se mostram variados. Nele, foi avaliada a complexidade encontrada pelos entrevistados para lecionar utilizando TIC. Foi obtido tais resultados: $44,4 \%$ como bastante difícil, $22,2 \%$ para pouca complexidade. Os itens: "muito pouco", "não, quase nada" e "não, nada" receberam a mesma porcentagem de $11,1 \%$. Isto revelou que os professores podem ter dificuldade devido à falta de estrutura, falta de incentivo, falta de treinamento pessoal ou do poder público. Ficando aqui, um importante assunto para ser tratado em pesquisas posteriores.

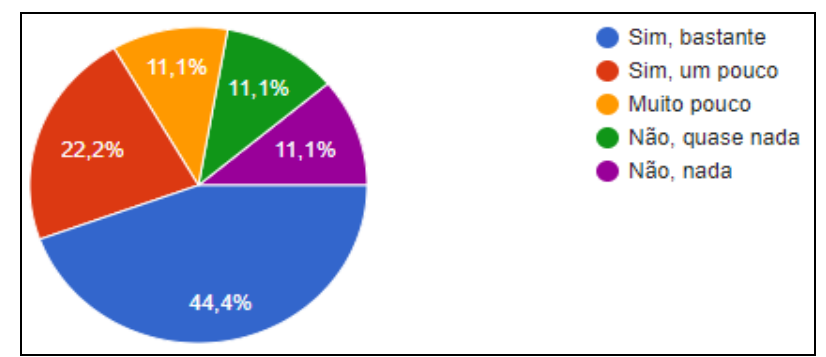

Gráfico 4. Complexidade para ensinar utilizando TIC.

\section{Conclusão}

A utilização das TIC se dá em múltiplos aspectos, possuindo diversas finalidades educacionais, empresariais e técnicos. Considerando-se tais utilidades, foi visto que o 
VIII Congresso Brasileiro de Informática na Educação (CBIE 2019)

Anais do XXV Workshop de Informática na Escola (WIE 2019)

propósito apresentado como questionamento deste documento se encaixa perfeitamente no âmbito educacional, tanto para professores quanto para os alunos beneficiados. É possível perceber que as TIC têm grande potencial e perfil adaptativo, tanto alunos quanto professores têm flexibilidade, aceitação e acessibilidade destas ferramentas.

De acordo com a pesquisa, as TIC apresentam um grande impacto social e técnico de maneira positiva, visto que o aprendizado e lecionamento melhoraram de forma considerável na escola referida. Desta forma, pôde-se concluir que as mesmas possuem grande utilidade e que podem ser aplicadas no processo ensino-aprendizagem de discentes e também possuem adaptabilidade de utilização por docentes.

Como trabalhos futuros tem-se a aplicação do projeto em outras escolas, inserindo uma maior quantidade de alunos, expandindo o público atendido haja vista o retorno adquirido. Dessa forma, planeja-se executar um novo estudo voltado a continuidade do aluno no âmbito escolar após a participação no projeto.

\section{Referências}

Bizelli, M., Fiscarelli, S. H. and Oliveira, L. (2009) "Conteúdos digitais para o ensino de cálculo: aceitação, demandas e expectativas dos alunos". In: IX Encontro Iberoamericando de Educação.

Dellos, R. (2015). "Kahoot! A digital game resource for learning”. International Journal of Instructional Technology and Distance Learning, 12(4), 49-52.

García-Valcárcel, A. and Martín, A. H. (2013). "Las Tecnologías de la información y la comunicación en el contexto educativo actual". In: Recursos Tecnológicos para la enseñanza e innovación educativa Madrid: Sintesis.

Leite, W. S. S., and Ribeiro, C. A. N. (2012). "A inclusão das TICs na educação brasileira: problemas e desafios". Magis: Revista Internacional de Investigación en Educación. P. 173-187.

Marçal, E., Andrade, R. and Rios, R. (2005). Aprendizagem utilizando dispositivos móveis com sistemas de realidade virtual. RENOTE.

Neto, R. P. B., Santana, A. M., Rocha, D. P. and Souza, A. (2015). "Robótica na educação: uma revisão sistemática dos últimos 10 anos". In Brazilian Symposium on Computers in Education (Simpósio Brasileiro de Informática na Educação-SBIE), p. 386.

Pacheco, J. A. (2001). Teoria curricular crítica: os dilemas (e contradições) dos educadores críticos. Revista Portuguesa de Educação, 14(1), 49-71.

Pires, S. M. (2009). As TIC no currículo escolar. EduSer - Revista de Educação. 1 (1).

Prata, C. L. (2005) "Gestão democrática e tecnologias de informática na educação pública: o ProInfo no Espírito Santo." (Doctoral dissertation, Dissertação (Mestrado em Educação) - Programa de Pós-Graduação em Educação, Universidade Federal do Rio Grande do Sul. Porto Alegre).

Santaella, L. (2007) “Cultura das Mídias Revisitada”. In: Linguagens líquidas na era da mobilidade. São Paulo: Paulus. 